\title{
Luciano Floridi e os problemas filosóficos da informação: da representação à modelização ${ }^{1}$
}

\author{
Luciano Floridi and the philosophical problems of information: from representation to \\ modeling
}

Maria Nélida Gonzalez

Pesquisadora $1 \mathrm{~A} \mathrm{CNPq}$

Professora do Programa de Pós-graduação em Ciência da Informação - UFF

E-mail: marianelidagomez@gmail.com

\section{Resumo}

No contexto da reconstrução crítica das concepções atuais acerca do conhecimento e da informação, este trabalho analisa a abordagem de Floridi dessa questão, através de seu mapa de problemas da Filosofia da Informação. Foram utilizados outros textos do autor, como o mapa da informação semântica, quando ajudavam a esclarecer seu ponto de vista. Considera-se que a opção pelo construtivismo, a subordinação da epistemologia à filosofia da informação e a rejeição da associação da informação com a representação, formam parte do esforço do autor para sustentar que a validação do conhecimento depende da informação, sendo que a validade da informação depende de processos de modelização baseados em dados.

Palavras-chave: Filosofia da informação. Floridi. Informação. Informação semântica. Dados.

\begin{abstract}
In the context of critical reconstruction of the current conceptions about knowledge and information, this paper analyzes the Floridi approach of this issue, through its map of problems in the philosophy of information. Other texts of the author are uses, as the map of semantic information, when contributed to the understanding of his point of view. It is considered that the choice of constructivism, the subordination of epistemology to the philosophy of information and the rejection of the association of information with representation, are part of the author's effort to sustain that the validation of knowledge depends on information, and the validity of the information depends on modeling process based on data.
\end{abstract}

Keywords: Philosophy of information. Floridi. Information. Information Semantics. Date.

É difícil estabelecer se as questões informacionais dão lugar a uma Filosofia da Informação, ou se ampliam, em escopo e abrangência, os problemas da investigação filosófica, em geral - ou as duas coisas. Para muitos, o que deveria ser perguntado, primeiro, seria se a informação poderia ser, ela mesma, objeto de problematização filosófica. Jonathan Furner (2008) diferencia questões filosóficas colocadas aos estudos da informação, das questões filosóficas indagadas pelos estudos da informação. Conforme o autor, na Filosofia foi diferenciando-se domínios de pesquisa, alguns muito bem estabelecidos, tal como a metafísica, a ética e a epistemologia; outros, mais recentes, são "filosofia de...", tal como a

\footnotetext{
${ }^{1}$ Trabalho desenvolvido com apoio do CNPq.
}

InCID: R. Ci. Inf. e Doc., Ribeirão Preto, v. 4, n. 1, p. 03-25, jan./jun. 2013. 
filosofia da linguagem ou a filosofia da ação, e remetem ao modo como os homens se relacionam com sua própria humanidade; outros mais, como a filosofia da educação, filosofia da tecnologia ou filosofia das arte, empreendem reflexões em torno à propósitos específicos. Outras áreas de pesquisa seriam desdobramentos da filosofia da ciência, tal como filosofia das matemáticas ou filosofia da física. Para Furner, este seria o caso da filosofia da Ciência da Informação, o que lhe outorgaria um status epistemológico.

Furner (2008) considera que essas demarcações são construções sociais, históricas, culturais, e nesse sentido, arbitrárias e contextuais. Wallerstein (1995, p. 2) vai mais longe, ao lembrar que tudo aquilo que o homem e as sociedades reúnem, o próprio homem e as sociedades separam, e isso afetaria os critérios de cientificidade que aspiram formalizar e unificar taxonomias acerca do conhecimento ou da sociedade.

Os estudiosos da Filosofia, por sua vez, não são muito afeitos às filosofias temáticas nem às ontologias regionais, e não têm aceitado com facilidade a demanda de um lócus investigativo próprio da informação.

Luciano Floridi vai empreender essa tarefa de outorgar dignidade filosófica à informação, nela mesma. Trata-se de elucidar problemas da Filosofia $d a$ informação, e não sobre a Filosofia da Informação, e uma das condições será evitar a mera translação a uma linguagem filosófica de problemas que sejam de outra ordem. Este trabalho é um esforço de análise do alcance e extensão de suas proposições, e das redes argumentativas que as sustentam.

Em uma investigação que define como filosófica Floridi não deixa de revelar um olhar formado na área das ciências da computação que faz uma leitura seletiva das tradições filosóficas. Um dos casos em que essa apropriação seletiva se manifesta, é com respeito à filosofia analítica, já que seus trabalhos reacendem e reformulam debates consubstanciados com os problemas que caracterizam, e em especial, com a teoria clássica da informação semântica (ver suas referências a Carnap e Bar-Hillel, 1952, por exemplo), mas não incorpora, ao mesmo tempo, muitas das premissas da lógica positivista. Do mesmo modo, distancia-se da filosofia acadêmica ou sistemática, criticando certas formas contemporâneas de escolasticismo (FLORIDI, 2011b) e olha com restrições à "filosofia continental" (ver sua resposta a Capurro, FLORIDI, 2008), mas isso não lhe impede de fazer um uso por vezes instrumental do pensamento filosófico europeu. Como exemplo, temos suas frequentes citações de Wittgenstein e das Investigações Filosóficas, que iluminam múltiplas 
possibilidades epistêmicas, mas podemos duvidar se o Wittgenstein das Investigações aceitaria suas afirmações de cunho ontocêntrico acerca do valor da informação.

Para Floridi, a Filosofia da Informação é um campo de pesquisa em construção, com direito à autonomia, e uma expressão reflexiva do giro informacional que, no mundo contemporâneo, designa as transformações que acontecem com o desenvolvimento das ciências e tecnologias da computação, da comunicação e da informação (FLORIDI, 2004a, 2011).

Retomando, num outro espaço argumentativo, algumas das inquietantes indagações de Le Moigne (1997), a abordagem filosófica de Floridi pode ser considerada como um esforço de reflexão sobre a modelização, na qual recorre as pressuposições ontológico-metafísicas como instância de justificação. Essa direção do perguntar ficaria bem ilustrada em sua proposta de apropriação metodológica (e metafórica) dos procedimentos computacionais pela filosofia, ou quando propõe a substituição narrativa do homem definido por seu ser político ou econômico, pelo homem demiúrgico, um construtor que não cria os ingredientes de sua composição, e cujos excessos semânticos estão sujeitos à ponderação dos dados.

Sua definição da filosofia da informação abrange assim o domínio e os procedimentos de investigação:

\footnotetext{
A filosofia da informação é o campo filosófico concernente com (a) a investigação crítica da natureza conceitual e os princípios da informação, incluindo suas dinâmicas, utilização e ciências, e (b) a elaboração e aplicação de metodologias teoréticas, informacionais e computacionais, a problemas filosóficos (FLORIDI, 2004a, p. 555 e 2011 b, p.14) $)^{2}$.
}

A missão dessa Filosofia da Informação não vai ser elaborar ou legitimar uma teoria unificada da informação, mas propiciar a constituição de uma família integrada de teorias, assumindo, para isso, algumas tarefas: a) analisar, avaliar e explicar os vários princípios e conceitos da informação, de suas dinâmicas e utilização; b) atender às questões que surgem em diferentes contextos de aplicação, e c) manter esse questionamento em permanente interconexão com outros conceitos chaves da filosofia, como Ser, conhecimento, verdade, vida, significado.

\footnotetext{
2" PI [Philosophy of Information] is a new philosophical discipline, concerned with (a) the critical investigation of the conceptual nature and basic principles of information, including its dynamics (especially computation and information flow), utilization, and sciences, and with (b) the elaboration of information-theoretic and computational methodologies and their application to philosophical problems"(FLORIDI, 2004a, p. 555).
}

InCID: R. Ci. Inf. e Doc., Ribeirão Preto, v. 4, n. 1, p. 03-25, jan./jun. 2013. 
A partir dessa abordagem sobre a Filosofia, Floridi apresenta um mapa dos problemas da Filosofia da Informação. A primeira pergunta será pela natureza da informação, na expressão grega, ti esti, o que é. Se essa primeira operação ontológica seria necessária e eficiente para diferenciar o atual domínio de pesquisa de outros domínios (como por exemplo, a Computação ou a Epistemologia da Informação), não seria suficiente para esclarecer quais as questões e objetividades do campo a constituir. A fim de subsidiar essa tarefa, Floridi (2004a; 2011) apresenta cinco grupos de problemas, agregados em torno de assuntos ou "palavras-chave" que, sem constituir um esquema de classificação nem uma "gramática", servirão de guia ou orientação para a construção de um mapa dos problemas investigativos próprios de uma filosofia da informação.

As palavras-chave são: informação, semântica, inteligência, natureza, valores.

Neste texto, apresenta-se inicialmente o mapa de problemas da filosofia da informação. E a seguir, trata-se de elucidar algumas pressuposições que resultam do mapa da informação semântica do próprio Floridi.

No mapa que, conforme Floridi (Quadro 1), guiaria a caminhada pelas arenas da problematização filosófica, a questão semântica da informação não só aparece em primeiro lugar, à luz da indagação ontológica, como é uma das palavras-chave agregadora de múltiplos problemas, e estará presente, de uma maneira ou outra, em todo o decurso do perguntar.

Quadro 1 - Mapa de problemas para uma Filosofia da Informação.

\begin{tabular}{|l|l|}
\hline \multicolumn{2}{|l|}{ Palavra-chave: INFORMAÇÃO } \\
\hline P1 & Que é informação? (ti esti) \\
\hline P2 & Quais são as dinâmicas da informação? \\
\hline P3 & É possível uma teoria unificada da informação? \\
\hline Palavra-chave: SEMÂNTICA \\
\hline P4 & Como os dados adquirem significado? \\
\hline P5 & Como dados significativos adquirem valor de verdade? \\
\hline P6 & Pode a informação explicar a verdade? (teoria informacional da verdade) \\
\hline P7 & Pode a informação explicar a significação? (semânticas informacionais) \\
\hline Palavra-chave: INTELIGÊNCIA \\
\hline P8 & Pode a cognição ser explicada em termos de processamento da informação? \\
\hline P9 & $\begin{array}{l}\text { Pode a inteligência natural ser satisfatoriamente analisada em termos de } \\
\text { processamento da informação? }\end{array}$ \\
\hline P10 & $\begin{array}{l}\text { Pode a inteligência natural ser satisfatoriamente e totalmente implementada } \\
\text { de maneira não-biológica? }\end{array}$ \\
\hline P11 & $\begin{array}{l}\text { Pode a abordagem informacional solucionar o problema da relação corpo- } \\
\text { alma? }\end{array}$ \\
\hline
\end{tabular}

InCID: R. Ci. Inf. e Doc., Ribeirão Preto, v. 4, n. 1, p. 03-25, jan./jun. 2013. 


\begin{tabular}{|l|l|}
\hline P12 & $\begin{array}{l}\text { Se a informação só pode ser aferida pela informação, existiria um círculo } \\
\text { informacional equivalente ao círculo hermenêutico? }\end{array}$ \\
\hline P13 & Pode a epistemologia ter como base uma teoria da informação? \\
\hline P14 & A ciência é redutível à modelização informacional? \\
\hline Palavra-chave: NATUREZA \\
\hline P15 & Qual o estatuto da informação em relação ao mundo natural? \\
\hline P16 & A informação pode ser natural? \\
\hline P17 & A natureza pode ser informacionalizada? \\
\hline Palavra-chave: VALOR \\
\hline P18 & Pode a ética da computação ter uma fundamentação filosófica? \\
\hline
\end{tabular}

Fonte - Dados organizados pela autora

O mapa de problemas se abre com a pesquisa ontológica, que gira em torno de três questões: o que é "informação", em que consistem suas dinâmicas, e se é possível, a partir desse esclarecimento ontológico, estabelecer uma teoria unificada da informação.

A primeira e grande pergunta será logo sobre o que é a informação, qual é sua especificidade (Problema 1, P1).

É interessante observar que a problematização ontológica de Floridi admite a priori algumas atribuições da informação: conheceríamos já que a informação deve ser quantificável, plausível de adição, estocável e transmissível. A partir disso, porém, ignora-se qual sua natureza específica. Atribuições e dúvidas estão assim ancoradas numa espécie de doxa ou senso comum que incorpora ao seu repertório certas restrições e possibilidades que surgiram pelo "giro informacional".

Três seriam as principais concepções de cunho ontológico: a) informação como realidade (por exemplo, um padrão de sinais físicas), denominando-se nesse caso informação ambiental ou ecológica; b) informação sobre a realidade, tal como seria o caso da informação semântica (que pode assim ser qualificada em relação a verdade ou falta de verdade); c) informação para a realidade, a qual teria a forma de "instruções" (e da qual a informação genética é um exemplo).

Floridi dedicará sua atenção às definições da informação como realidade ou sobre a realidade, as quais dariam lugar a seis principais abordagens: a) teoria matemática da codificação e comunicação de dados/sinais; b) abordagem probabilística (que seria desenvolvida por Bar-Hillel e Carnap, 1953; Bar-Hillel 1964; Dretske 1981, todos citados por Floridi, 2011a); c) abordagem modal, que define a informação em termo do espaço modal e 
de mundos possíveis; c) abordagem sistêmica; d) abordagem inferencial, que define a informação em função do espaço de inferências e e) abordagem semântica.

A abordagem semântica é a adotada pelo autor, que é quem define a informação em termos do espaço dos dados. A informação semântica consiste em dados bem formados, significativos e verídicos ${ }^{3}$ (FLORIDI, 2004a, p 561).

É interessante lembrar, comparativamente, o horizonte de definição escolhido por Wersig e Windel (1985), os espaços da ação, permitindo uma orientação pragmáticoinstrumental de entendimento da informação, como modalidade ou dimensão da ação. A relação entre as abordagens semânticas e pragmáticas da informação é um dos assuntos que deverão ser retomados, em outro momento.

A segunda ordem de problemas, na mesma sequência ontológica, refere-se às dinâmicas da informação (P2), questão que para Floridi não teria sido corretamente abordada. Primeiro, porque é confundida com questões acerca dos processos de gestão da informação (tal como quando se fala busca de informação, mineração de dados, armazenagem, recuperação, editoração, distribuição, verificação, controle de qualidade, avaliação, entre outras instâncias). Segundo, porque a questão tem sido cooptada pela teoria matemática da transmissão de dados, a qual visa a dar conta somente da instância física da comunicação/transmissão da informação.

Trata-se de dinâmicas plurais: 1) as que acontecem na constituição e modelização de ambientes de informação; 2) as próprias dos ciclos de vida da informação e 3) as específicas da computação, em seus dois sentidos, de processamento algorítmico e processamento da informação (ver FLORIDI, 2011b, p.14-15).

A principal pergunta pelas dinâmicas, porém, precisa ser colocada com maior rigor: como é possível acontecer, neles mesmos, o fluxo e transmissão de informação? Trata-se de esquadrinhar essas dinâmicas como explanandum e não naturalizá-las, passando a ser parte do explanans ${ }^{4}$.

O terceiro problema (P3), se expressa na pergunta: é possível uma teoria unificada da informação? a qual Floridi (2011) responde de maneira negativa.

\footnotetext{
${ }^{3} \mathrm{Na}$ formulação de uma "teoria semântica forte", é condição os dados serem verdadeiros, e não só plausíveis de verdade ou falsidade.

${ }^{4}$ Algo que pareceria acontecer, a nosso ver, com algumas das teorias da mediação
}

InCID: R. Ci. Inf. e Doc., Ribeirão Preto, v. 4, n. 1, p. 03-25, jan./jun. 2013. 
Dada a existência de uma pluralidade de conceitos, modelos e explicações referentes à informação, uma teoria unificada implicaria pressupor uma entidade, essência ou princípio universal e invariável como objeto preferencial, tal que eliminara todas as outras concepções e definições concorrentes. Para Floridi, uma teoria unificada da informação só poderia ter efeitos reducionistas, entre outras razões, porque desativaria numerosas questões ainda sem responder. Abandonada a hipóteses de uma teoria unificada da informação, seria plausível, porém, falar de "[...] uma rede de conceitos logicamente interdependentes mas mutuamente irredutíveis". Optando-se pela posição não-reducionista, fica ainda a dificuldade de estabelecer"[...] como os vários significados de informação estão relacionados, se alguns desses conceitos são mais centrais ou fundamentais que os outros e deveriam ser privilegiados" (FLORIDI, 2004a, p. 563).

Com a palavra-chave semântica serão reunidos problemas referentes à relação entre informação, significado e verdade.

$\mathrm{O}$ autor estabelece premissas delimitadoras do escopo e abrangência dessa problematização: "[...] a informação semântica pode ser satisfatoriamente analisada em termos de dados bem formados, dotados de sentido e verídicos (truthful)" (FLORIDI, 2004a, 563). No perguntar orientado pelas perspectivas de Floridi, o vínculo informação-semântica vai preceder e condicionar a vinculação informação-conhecimento.

Utilizando-se dos procedimentos que denomina de abstração, primeiro, o autor vai problematizar como um dado adquire significado $(P 4)$ e sendo significativo, valor de verdade (P5). O problema do "data-grounding" (P4), indaga pelo significado intrínseco do dado, independentemente da mente ou de qualquer agência interpretante.

Os dados "brutos", silentes, lembram uma premissa implícita do empiricismo: a existência de um solo comum, algo assim como a base de uma experiência neutra e a priori, que precede e sustenta todas as aventuras culturais e as pluralidades epistêmicas, e que agora parece re-apresentar-se como o dado. Se aquela premissa teria sido desativada pelos pósempiricistas $^{5}$, qual seria a vantagem em reaparecer como a instância proto-epistêmica do dado? Seria uma demanda da convergência digital, que iguala plurais meios, linguagens e codificações, imagens e textos, escrita e fala, e inclui sob uma mesma operação de modelização digital o orgânico e o inorgânico, o analógico e o virtual?

\footnotetext{
5 Essa pressuposição implícita na concepção empírica moderna do conhecimento é debatida pelos pósempiricistas contemporâneos, como Kuhn (1975) e Feyerabend (1989), os que pretendem tê-la superado com a teoria dos paradigmas e o conceito de incomensurabilidade.
}

InCID: R. Ci. Inf. e Doc., Ribeirão Preto, v. 4, n. 1, p. 03-25, jan./jun. 2013. 
O papel outorgado ao dado e a modelização implicam por certo uma demarcação excludente dos problemas a investigar: primeiro, a informação é dissociada da representação, como algo que remeta à cópia, ao espelho ou à mente e, segundo, a esfera informacional excede a esfera digital ou computacional. A representação tinha como função salvar a brecha que a modernidade abriria entre o real e o homem, e essa brecha agora reaparece, como o problema da brecha entre o agente intencional e o dado, que exibe e oculta o mundo real. Tal seria o problema do "frame", do quadro de referencia.

Na arguição de Floridi, uma vez considerado o caráter significativo do dado, ele admitiria valores de verdade. Os problemas sobre o caráter alético do dado, parecem reformular os problemas da relação entre significado e verdade formulados pela filosofia analítica, que buscara a solução pela relação entre a lógica e a linguagem e no plano da semântica formal. A problematização de Floridi, porém, traçará novamente uma distância entre a virada linguística, iniciada pela filosofia analítica, e o que denomina o giro informacional. Para isso, examinará as questões sobre o caráter alético do dado e da informação a partir da metodologia dos níveis de abstração; são certos procedimentos que permitiriam lidar com a questão do significado e da verdade, associadas ao dado e à informação, sem referência aos usos e figuras da linguagem. A informação terá o compromisso teórico e prático de suprir essas ausências.

Indaga a seguir se uma teoria da informação poderia, melhor que o fazem outras teorias, explicar a verdade, dar conta da verdade (PO), ou, ao menos, colocar em evidência as restrições explanatórias das outras abordagens.

Do mesmo modo, caberia perguntar se a informação oferece uma explicação do significado (P7), ou, ao menos, e ainda quando não tiver uma função de verdade, se o significado teria a potencialidade de mudar ou de alterar, um contexto de informação.

Em alguns momentos, as questões colocadas acerca da informação semântica parecem demandar a radicalização da problematização ontológica, reformulando os desafios do empiricismo extremo: "se o homem desaparecer do universo, desaparecem ou não desaparecem, o dado e a informação?" ${ }^{\text {. }}$

\footnotetext{
${ }^{6}$ Devemos esta pergunta a nosso primeiro professor de Epistemologia, Prof. Raymundo Pardo, autor do Ensayo sobre los integrantes racionales, Sociedad Argentina de Filosofía, 1949. De algum modo, esse nível do perguntar reaparece no tópico natureza, e na apresentação do dito problema de Winer.
}

InCID: R. Ci. Inf. e Doc., Ribeirão Preto, v. 4, n. 1, p. 03-25, jan./jun. 2013. 
Consideramos importante para avançar no entendimento de Floridi e do valor heurístico de seus problemas, lembrar novamente suas teses construtivistas e sua rejeição das teorias da representação. De um ponto de vista informal e narrativo, o lócus do agente epistêmico da representação e do sujeito hermenêutico da interpretação, seria ocupado agora por um homem demiúrgico, que se relaciona com o real pela modelização. O filósofo é comparado primeiro aos engenheiros e depois, a um designer conceitual, assim como o inforg, o homem que emerge na virada informacional, ficaria caracterizado pelas atividades poiéticas, e não pelas técnicas, contemplativas ou retóricas. Agente imprescindível dos processos de semantização, espécie que se caracteriza por seus excessos semânticos, essa semantização seria uma operação de concepção e não de representação ou de interpretação. Caberia perguntar qual agência, para que, que informação, qual é a modelização e quais os dispositivos de informação que reivindicam hoje esse lugar vazio deixado pelo sujeito moderno e seus recursos instrumentais.

O terceiro agregado, que recebe a etiqueta de inteligência, reúne problemas que transitam tanto nos domínios da informação e da computação quanto no campo das teorias do conhecimento e da filosofia da ciência, aos que hoje deveriam agregar questões das ciências da cognição. O ponto de partida seria o problema geral do conhecimento, em que consiste e como se obtém, associado neste contexto ao entendimento das dinâmicas da informação. Cabe lembrar que este seria um território já explorado pela Inteligência Artificial, a qual chegou a pensar-se como a totalidade do campo da filosofia da informação, mas do qual, para Floridi (2011, p 2-5), teria sido uma versão prematura.

Uma série de perguntas visariam a esclarecer quais as finalidades e o domínio de exercício da inteligência natural e da inteligência artificial, suas relações e diferenças, numa indagação que vai além de perguntas do tipo "As máquinas pensam?" ou "O cérebro é um computador digital?". Para Floridi, os conceitos informacionais são tão fortes, que, num dado nível de abstração, qualquer coisa pode ser apresentada como sistema de informação, numa espécie de pan-computacionismo. O verdadeiro problema seria demonstrar quando um sistema físico não é um sistema de informação (FLORIDI, 2004a, 566 e ss.).

Algumas das questões, denominadas como o "problema de Descartes" (P8), indagariam se formas de cognição podem ser total e satisfatoriamente analisadas em formas de processamento da informação, a certo nível de abstração? 
Em seu conjunto, as perguntas pela inteligência seguirão dois caminhos: a) relacionar a inteligência humana e o processamento computacional; b) elucidar as relações entre informação, inteligência e conhecimento - problemas a serem compartilhados com a epistemologia e a filosofia da ciência. Uma das primeiras questões é indagar pela diferença entre a função dos dispositivos de inteligência artificial (IA) e a inteligência natural humana. $\mathrm{Na}$ exposição de Floridi, os dispositivos de IA só identificariam e processariam dados (padrões de diferenças e invariâncias não interpretados); a inteligência humana identifica e processa principalmente informação (ver FLORIDI, 2004a, p. 569).

A diferenciação e relação entre informação, dado e inteligência humana, pode desdobrar-se numa complexa série de problemas, tal como: pode a inteligência natural ser satisfatoriamente analisada em termos de processamento da informação? (P9); pode a inteligência natural ser satisfatoriamente e totalmente implementada de maneira nãobiológica? (P10); pode a abordagem informacional solucionar o problema da relação corpoalma? (P11). A posição dessa linha demarcatória entre o natural e o artificial, não seria imutável. Para Floridi, se os computadores são descritos como máquinas sintáticas, cabe lembrar que neles a semântica está negligenciada, mas não ausente. Em qualquer caso, hoje, o nível mais alto ao que chegaria a inteligência artificial, seria o nível elementar do qual vai partir a inteligência humana natural, a discriminação dos dados como diferença.

$\mathrm{Na}$ mesma ordem de questões epistêmicas, surgiria o problema de como auditar a informação (P12), se é que a informação só poderia ser conferida por mais informação; teríamos que falar de um "círculo informacional" semelhante ao círculo hermenêutico. Esta reflexão reconduziria ao debate moderno sobre a aceitabilidade de alguma forma de realismo, conforme a qual nossa informação acerca do mundo capturaria algo da maneira de ser do mundo, se bem não de maneira literal.

Qual seria, enfim, a relação entre a epistemologia e a teoria da informação (P13)? Se o conhecimento pressupõe a informação, à luz da hipótese de um continuum conforme a qual "o conhecimento encapsula a verdade porque encapsula informação semântica" (FLORIDI, 2004a, p. 571), a filosofia e teoria da informação precederiam à epistemologia, assim como a informação tem prioridade constitutiva sobre o conhecimento. Para Floridi, o conhecimento seria um fenômeno mais raro que a própria raridade da informação. Para as abordagens internalistas ou intencionalistas da informação, porém, é a informação que depende dos processos de conhecimento para sua validação. 
Radicalizando a problematização, Floridi (2004a, p. 571) se pergunta se podem existir estados informacionais que não sejam estados epistêmicos e, colocando em xeque o alcance e valor do "giro informacional", pergunta se finalmente a ciência é redutível à modelização informacional $(P 14)^{7}$.

A quarta palavra-chave, natureza, conduz de novo à pesquisa filosófica pelos rumos de uma ontologia da informação. Indaga-se agora pelo lócus da informação, em relação ao mundo dos "sistemas físicos e biológicos", o orgânico e o inorgânico.

Mantidas atribuições já definidas, Floridi sustenta que não seria cabível pressupor um mundo totalmente caótico e imprevisível; nele, não teria cabida a informação. Aquele $a$ priori, que estaria justificado tanto conceitualmente como pelas características do giro informacional, não indicaria, porém, o lugar que a informação ocupa na esfera da natureza.

Esta opacidade do lócus da informação na physis vai ser desdobrada em três perguntas: a) qual é o estatuto ontológico da informação? (o problema de Wiener ${ }^{8}$, P15); b) qual a possibilidade de naturalizar a informação? (o problema da localização, P16, também relacionado à questão já apresentada da "semantização do dado") e c) poderia a natureza ser informacionalizada $(P 17)$ ?

Para melhor ponderar a importância destas questões, e sua repercussão nos estudos da informação, caberia comparar rapidamente a problematização ontológica de Floridi e sua proposição da prioridade proto-epistêmica do dado, com a teses de Frohmann (2004), da prioridade ontológica do documento.

Para Frohmann (2004), é no documento ou numa plataforma telemática que a informação acontece por atribuição, conforme contextos e dinâmicas socioculturais. Frohmann colocará a informação sob a prioridade ontológica do documentar, efeito intencional e não intencional de práticas sociais, situadas num dado horizonte civilizatório.

Floridi, por sua vez, coloca sua reflexão num horizonte ontológico e pré-epistêmico, por pressuposição, num lócus ainda indiferenciado entre natureza e cultura. Nesse lócus idealizado, o dado opera num espaço de mediação que se apresenta como substituição das

\footnotetext{
${ }^{7}$ Estas questões estariam relacionadas a outras perguntas pela relação entre informação, verdade e significação (P6, P7).

${ }^{8}$ WIENER, N. Cybernetics or control and communication in the animal and the mchine. Cambridge: MIT Press, 1948 apud FLORIDI, 2011a)
} 
práticas da linguagem e das representações subjetivas do mundo exterior. O dado seria assim uma espécie de mediação que, universal em sua função, condiciona caso a caso as possibilidades e os constrangimentos de toda modelização informacional, tenha como conteúdo texto e imagem, redes de coisas e pessoas, infra-estruturas ou narrações.

O problema de Wiener serve a Floridi para trazer à reflexão outras concepções sobre o lócus ontológico da informação. As orientações fisicalistas dariam sustentação ontológica às abordagens da engenharia da computação, para a qual não seria pensável a informação sem implementação física (associando software e hardware). Como contra-argumentação, poderia pensar-se num ambiente noético, tal como a noosfera de Teilhard de Chardin (1965), ou imaginar caráter noético do que é por analogia com o sensorialismo de Berkeley (2010), "ser é ser percebido" (esse est percipi). Uma terceira opção consistiria em afirmar que a informação é uma categoria ontológica independente, alheia ao dualismo substância extensa -substância pensante. Para Wiener (1948 ${ }^{9}$ apud FLORIDI, 2011a), a informação não é matéria, nem energia: admitida, porém, essa diferença ontológica, seria necessário explicar como ela vai a relacionar-se com as ordens da natureza e da cultura.

Numa de suas formulações mais radicais, para Floridi (2010, o problema do "lócus" ontológico pergunta pelo modo de ser de uma informação tal, que não dependesse de alguma forma de vida capaz capturá-la, representá-la ou interpretá-la. Tal informação no mundo ou do mundo seria chamada de informação ambiental, e não requer para ser aquilo que é, nem uma representação cognitiva nem um processamento computacional. Tratar-se-á de um conteúdo semântico independente de toda forma de vida e representação? Não teria tampouco como condição ter um suporte físico, já que ela é ou está inserida na própria estruturação do mundo físico ou exterior. O exemplo trazido por Floridi são os anéis concêntricos visíveis no corte de uma árvore, que permitiriam inferir sua idade. O problema de um externalista (como Dretske, 2007), seria perguntar como a informação ambiental pode ser acessada por um agente, que possa interagir com ela. Um intencionalista (como Fodor) deverá explanar como uma informação dessa qualidade vai depender de um sujeito inteligente (FLORIDI, 2011b).

Em síntese, sendo que a localização ontológica afeta a relação entre a informação e o que é informado (information-infomee), questiona-se tanto a autonomia dos termos envolvidos quanto a qualidade dessa relação ou, ainda, se existiria um terceiro estado, de

\footnotetext{
${ }^{9}$ WIENER, N. Cybernetics or control and communication in the animal and the mchine. Cambridge: MIT Press, 1948
}

InCID: R. Ci. Inf. e Doc., Ribeirão Preto, v. 4, n. 1, p. 03-25, jan./jun. 2013. 
modo que a informação não for nem da ordem da natureza, nem da ordem da inteligência ou da cultura (FLORIDI, 2004a, p. 574).

Perguntar pela possibilidade de que a natureza nela mesma seja informacional, coloca no centro da indagação o universo, nele mesmo; trata-se de saber se processos considerados naturais, como as relações causais, poderiam ser considerados como dinâmicas informacionais. Para Floridi (2004a, p. 574), essa problemática (P17) desdobra-se em muitas e difíceis perguntas: qual a diferença entre uma realidade virtual ou material?; qual o significado de vida artificial?; quais as relações metateóricas entre a Filosofia da informação e a Física, dado que se o Universo for feito de informação, a física quântica seria uma teoria da informação física?

O quinto cluster de problemas é apresentado sob a palavra-chave de valor. Questões normativas e orientadas por valor acompanhariam as evidencias de que as tecnologias de informação e comunicação são capazes de afetar os sistemas e as formas de vida. A ética da computação teria surgido para atender às demandas normativas que crescem a par dos efeitos negativos e não desejados do giro informacional. A partir de 1970, para Floridi (2011), ela se desenvolve seguindo dois caminhos: primeiro, investindo na análise dos problemas emergentes, com a finalidade de gerar uma tomada de consciência dos profissionais, dos políticos e da opinião pública; depois, tratando de identificar medidas táticas e compensatórias que corrigiriam os efeitos negativos.

À luz da filosofia da informação, as questões éticas (não já como ética da computação) teriam a missão de olhar problemas sociais produzidos pelo giro informacional, desde o momento de sua constituição e não a posteriori, considerando os efeitos positivos ou negativos dos novos recursos informacionais. Não é que eles não sejam importantes, mas Floridi enfatiza que seria preciso avaliá-los de um ponto de vista estratégico e global, e não só por análises micro, situacionais, que só levariam a soluções táticas e parciais.

As micro-éticas (FLORIDI, 2005) seriam aquelas construídas em torno de três pontos de vista acerca algum valor moral informacional: considerando a informação como recurso, do ponto de vista do seu uso; considerando-a como produto, quando recursos de informação usados para gerar outra informação; na perspectiva do ambiente informacional, enquanto afetado pelas intervenções de uma agência na geração e uso de informação. 
A problematização ética da informação como recurso, pelo uso, vai de encontro às éticas intelectuais, que destacarão o componente epistêmico das avaliações e ações morais, e consideram de algum modo o desvio moral como deficiência de informação (com informação suficiente e de qualidade o desvio de conduta poderia ter sido evitado). A responsabilidade moral é de grau análogo ao teor e qualidade das informações que orientam a conduta ou o julgamento avaliativo. A esta linha de raciocínio pertencem as questões normativas e valorativas referentes à disponibilidade, acessibilidade e exatidão (accuracy) da informação, a credibilidade dos recursos de informação e as assimetrias geradas pela brecha informacional (ver FLORIDI, 2005, p 4 e ss.).

Considerando a informação como produto, a problematização ética de seu valor atinge não seu uso, mas principalmente seu processo de produção, e as consequências éticas das condições em que ele se realiza, tal como a responsabilidade com a seleção de alternativas, tal como a escolha de procedimentos vantajosos aos interesses particulares, mas nocivos de um ponto de vista coletivo ou global. Entre os problemas éticos da informação, nesta orientação, Floridi lembra as questões da accountability (prestação de contas), da mentira, do exercício do testemunho, entre outras ${ }^{10}$ (ver FLORIDI, 2005, p 5 e ss.)

A terceira linha de problematização, no escopo das micro-éticas, remeteria às ações $e$ avaliações morais que afetam o ambiente informacional, atingindo a ecologia da informação. $\mathrm{O}$ ataque dos hackers a um site ou sistema de informação seria um exemplo destes problemas, que inclui todo caso de vandalismo (desde a destruição de bibliotecas e arquivos à disseminação de vírus), e que abrange questões que afetam a propriedade intelectual, a liberdade de expressão, a censura, o controle e filtragem de conteúdos.

Essas primeiras abordagens dos problemas éticos, do ponto de vista positivo, tem dado visibilidade aos aspectos valorativos e normativos da informação, mas, ao mesmo tempo, Floridi critica os efeitos de fragmentação desse domínio de indagação. Para o autor, a Filosofia da Informação contribuiria para colocar os problemas informacionais de caráter moral, no escopo e abrangência de uma macro-ética da informação, tal que nela se incluam, articulem e superem as análises táticas e situacionais do modelo tripartite (FLORIDI, 2005, p. 6). Por outro lado, podem surgir outros efeitos de dispersão das questões éticas, dado que com a ampliação em escopo e abrangência, a Ética da Informação pode diluir-se numa

\footnotetext{
${ }^{10}$ As "pragmatic rules of communication à la Grice" seriam pertinentes a este tipo de problemas.(Floridi, 2009, p. 5).
}

InCID: R. Ci. Inf. e Doc., Ribeirão Preto, v. 4, n. 1, p. 03-25, jan./jun. 2013. 
pluralidade de campos problemáticos (como o das éticas profissionais, a ética da pesquisa, entre outras).

A Ética, ao mesmo tempo, não esgota os problemas acerca do valor da informação. Para o próprio Floridi, quem, em outros trabalhos, sustentará que a informação é dotada de valor nela mesma (não por seus usos, seus efeitos), é importante refletir sobre os critérios de relevância, quiçá a primeira observação de um valor de informação, objeto de uma literatura clássica da Ciência da Informação e dos estudos dos sistemas de informação (FLORIDI, 2008).

Neste trabalho, será aproveitada a extensão das questões da ética da informação, para fazer a passagem do mapa de problemas de filosofia da informação ao mapa da informação semântica de Floridi. Trata-se de elucidar algumas das premissas que sustentam, de maneira mais ou menos explícita, a escolha e apresentação dos problemas da Filosofia da Informação, por Floridi, fazendo uma rápida e inicial incursão no campo de um movimentado debate iniciado por seus desafios intelectuais, em que novos ângulos desses problemas serão iluminados pelas proposições antagônicas ou complementares do autor e seus críticos.

Conforme Capurro, Luciano Floridi, junto a Jeff Sanders, teria estabelecido bases institucionais para uma ética da informação, ao criar o "Information Ethics Group" (IEG), na Universidade de Oxford, com a colaboração do Laboratório de Computação e da Faculdade de Filosofa (ver CAPURRO, 2008, p. 168). Floridi, ao mesmo tempo que construiu um lugar institucional de estudos e debates, vai buscar auxílio numa Filosofia da Informação para dar ancoragem a uma ética agora informacional, e não computacional (FLORIDI, 2002, entre outros).

Conforme for lembrado, as micro éticas fariam remissivas a um ator-agente que usaria alguma informação (informação como recurso) para gerar alguma informação (informação como produto) e, ao fazê-lo, interviria no ambiente informacional (informação como alvo ou variável dependente). É essa orientação epistêmica e antropocêntrica da ética que será objeto da crítica de Floridi, e a justificação de sua contraproposta de uma ética ontocêntrica para uma ecologia da informação.

Compreender a natureza da EI [Ética da Informaçãp] ontologicamente ao invés de epistemologicamente modifica a interpretação do alcance de uma EI. Não só uma EI ecológica pode obter uma visão global de todo o ciclo de vida da informação, superando, assim, os limites de outras abordagens microéticas, mas também pode 
reivindicar um papel como macroética, isto é, como uma ética que diz respeito a toda a esfera da realidade (FLORIDI, 2002 ${ }^{11}$ ).

Sem dúvida, Floridi oferece pontos de vista interessantes sobre o alcance e extensão do estatuto ético da informação, críticos em relação às demarcações do biocentrismo e ao computacionismo. Ao mesmo tempo, suas argumentações, em geral, permitem interpretações conflitantes, que oscilam entre a ancoragem da informação em compromissos ontológicos ou sua imersão naturalizadora em certezas metafísicas. Conforme Capurro, a investigação ética de Floridi buscaria suas raízes em conceitos construídos no cerne do pensamento grego, tais como ideia, eidos, morphe e typos; conceitos todos traduzidos ao latim como forma, cujo núcleo do significado seria: “dar forma a algo". É a partir dessa orientação ontológica que Floridi elaboraria seu conceito de informação, rejeitando as versões epistêmicas e de cunho intencionalista.

Utilizando-se daquele discurso metafísico que se originara na filosofia grega, Floridi vai afirmar que o Ser seria mais elementar que a vida, sendo que o Ser pode ser visto em termos de informação, em determinado nível de abstração, de modo que, nesse contexto procedimental, a informação poderia ser entendida como a manifestação elementar do Ser. STAHL, de maneira mais radical, afirma ao respeito que "a realidade é entendida como informação, e a realidade é a fonte da ética" (STAHL, 2008). Floridi apresenta assim uma abordagem objetivista da informação e uma concepção da informação e da infoesfera como dotadas de valor, nelas mesmas.

Do ponto de vista da meta-ética, EI [ética da informação] é uma macro-ética
"naturalista" e "realista": as características ontológicas e o "bem-estar" [well-being]
da infoesfera proveem bases "objetivas" (orientadas ao objeto) para o julgamento do
correto e do errado e geram razões "objetivas" para a ação (são iniciadoras de ação,
enquanto o sistema moral, baseado na natureza e aperfeçcoamento da informação e
das correspondentes demandas morais, é universalmente vinculante, ou seja, vincula
todos os agentes em todo tempo e lugar (FLORIDI, 1999, p. 49 (Trad. Nossa)

Enuncia, assim, quatro "leis morais" que determinariam o que é certo e errado, do ponto de vista da maximização e excelência da infoesfera, evitando a entropia ${ }^{12}$ e promovendo o bem estar informacional pelo aumento em extensão (quantidade de

\footnotetext{
11 "Understanding the nature of IE ontologically rather than epistemologically modifies the interpretation of the scope of IE. Not only can an ecological IE gain a global view of the whole life-cycle of information, thus overcoming the limits of other microethical approaches, but it can also claim a role as a macroethics, that is, as an ethics that concerns the whole realm of reality" (FLORIDI, 2002).

12 "The term entropy does not stand for the physicist's view of the term but corresponds with Floridi's concept of information and means the "destruction, corruption, pollution and depletion of informational objects" (FLORIDI, 2006, p. 26), which means “any form of impoverishment of being” (ibid.)” (STAHL, 2008).
}

InCID: R. Ci. Inf. e Doc., Ribeirão Preto, v. 4, n. 1, p. 03-25, jan./jun. 2013. 
informação), o aperfeiçoamento (qualidade da informação) e o enriquecimento (variedade da informação) da infoesfera.

Um dos pontos que atrai mais críticas ao pensamento de Floridi será justamente essa abordagem ontocêntrica e sua afirmação de um valor intrínseco da informação. Para Capurro (2008), o valor não designa uma propriedade das coisas, é antes um efeito de nossas relações com as coisas e com os outros. As coisas, naturais ou artificiais, são nelas mesmas sem valor, assim como o homem por sí mesmo não é plausível de valoração, é in-valuáble - já que ele e é quem assume os julgamentos de valor.

Conforme já fora observado, Floridi mantém seu questionamento em domínios já recorridos pela filosofia analítica, tal como o problema do vínculo entre significado e verdade, mas não parece compartilhar a virada linguística que ela inicia, nem a rejeição das questões ontológicas pelo positivismo lógico. Isto tem consequências significativas na problematização das relações entre conhecimento e informação.

O mapa da informação semântica (FLORIDI, 2013; CHEN; FLORIDI, 2012), estabelece uma sequência que coloca o dado como condição da informação (ex ante), e a informação como condição constitutiva do conhecimento e de sua validade (ex post), de modo que as condições aléticas da informação (que ela seja verdadeira) dependem numa primeira instância da constituição alética do dado, e não de sua decodificação e aferimento pelo conhecimento.

O problema da relação entre informação e verdade admite, porém, posições controversas. Se para alguns não há informação semântica que não seja verdadeira, para outros, a informação é aléticamente neutra. O valor epistêmico da informação não seria da ordem da verdade, mas de outra ordem, tal como a confiabilidade, exatidão (accuracy), credibilidade. É o caso das concepções que colocam a verdade como sendo atribuível somente a discursos declarativos e proposições assertóricas. Essa demanda de estruturas proposicionais como sustentação do julgamento de validade nas argumentações, plausíveis então de justificação argumentativa e de orientação à verdade, encontra-se expressa de diversas maneiras, em Habermas (1997). Nesse uso proposicional da linguagem sustenta-se a dimensão epistêmica e intersubjetiva do agir comunicativo.

Todo pensamento completo é determinado por um estado de coisas desde o ponto de vista de sua constituição por um conteúdo assertórico ou expresso numa proposição assertórica; ao mesmo tempo, é objeto de um ato de apreciação crítica dos sujeitos falantes e pensantes, que podem tomar posição acerca desse caráter assertórico de 
seu conteúdo proposicional -dizendo sim ou não.[...] A avaliação afirmativa de um pensamento ou sentido assertórico de uma proposição pronunciada coloca em jogo a validade do juízo ou da frase[...] (HABERMAS,1997, p.29-30).

O papel outorgado ao dado, por Floridi, parece deslocar à verdade de seu lócus discursivo-proposicional que, para alguns, seria apontado por Aristóteles ${ }^{13}$. Cabe lembrar com mais detalhe sua concepção do dado.

O dado é a matéria prima (stuff) da qual a informação é feita. O ser bem formado de dado quer dizer que os dados estão corretamente agregados (clustered together), conforme a regras do sistema, código ou linguagem escolhido, ou seja, conforme uma sintaxe. Trata-se, porém, de regras de estruturação que não são necessariamente linguísticas. No exemplo usado na enciclopédia de filosofia de Stanford, mostra as imagens de um manual que explica, pela posição da figura de um par de carros, como se pode recarregar a bateria de um carro, com o suporte da bateria de outro carro. A informação semântica acontece pelo fato dos dados que lhe são pertinentes serem bem formados e significativos. De maneira análoga aos dados que a nutrem, a informação semântica não é necessariamente linguística (FLORIDI, 2013). A mobilidade do dado entre o mundo físico, o meio e o código, seria a garantia da independência da informação semântica do meio físico, do formato e da linguagem. Conforme Floridi,

\begin{abstract}
A dependência de informação da ocorrência de dados sintaticamente bem formados, e dos dados da ocorrência de diferenças diversas implementáveis fisicamente, explicaria por que a informação pode ser facilmente dissociada do seu suporte. $\mathrm{O}$ médio, formato e linguagem concretos em que a informação semântica é codificada, são as vezes irrelevantes e podem ser desconsiderados. Em particular, a mesma informação semântica pode ser analógica ou digital, impressa em papel ou visualizada em uma tela, expressa em Inglês ou em alguma outra língua, em palavras ou imagens ( FLORIDI, 2013 ${ }^{14}$ ) .
\end{abstract}

Floridi não deixa de preservar, em novo contexto, muitas das propriedades que a definição clássica da semântica formal atribuiu à informação. Carnap e Bar-Hillel (1952) ${ }^{15}$ desenvolvem o que hoje se conhece como a Teoria Semântica Clássica da Informação. Para os

\footnotetext{
${ }^{13}$ Ver a crítica de Heidegger à abordagem proposicional da verdade (HEIDEGGER, 1951, p. 235) entre outras.

${ }^{14}$ The dependence of information on the occurrence of syntactically well-formed data, and of data on the occurrence of differences variously implementable physically, explain why information can so easily be decoupled from its support. The actual format, medium and language in which semantic information is encoded is often irrelevant and hence disregardable. In particular, the same semantic information may be analog or digital, printed on paper or viewed on a screen, in English or in some other language, expressed in words or pictures. FLORIDI, 2013.

15 "Bar-Hillel and Carnap's seminal account of semantic information... measures the information yield of a statement within a given language in terms of the set of possible states it rules out and a logical probability space over those states. The general idea is based on the Inverse Relationship Principle, according to which the amount of information associated with a proposition is inversely related to the probability associated with that proposition. This account will henceforth be referred to as the theory of Classical Semantic Information (CSI). D'AFONSO, 2011
}

InCID: R. Ci. Inf. e Doc., Ribeirão Preto, v. 4, n. 1, p. 03-25, jan./jun. 2013. 
autores, o "problema semântico" da comunicação, que fora apresentado por Weaver, referente às relações de interlocução entre emissor e destinatário, seriam questões da pragmática, e não propriamente semânticas:

Nossa teoria se localiza total e explicitamente dentro da semântica. Não se trata, porem, do que tem sido denominado por Weaver [...] "o problema semântico" da comunicação, o qual, tal como ele o define, é concernente à identidade, ou aproximação satisfatoriamente aproximada, da interpretação do significado pelo receptor, se comparado com o significado intencionado pelo emissor. Temos preferido considerar uma investigação em que emissor e destinatário estão explicitamente envolvidos, como pertencentes à pragmática (BAR-HILLEL; CARNAP, 1952, p. 2). ${ }^{16}$

Carnap e Bar-Hillel (1952), após reconhecerem as condições pragmáticas da informação, vão a excluí-las de modo imediato, ao propor uma situação "ideal" que elimina, de fato, qualquer das variações linguísticas e culturais de práticas de informação, vinculadas aos modos intersubjetivos de interlocução e as variações empíricas de seus contextos referenciais. Por definição, a informação semântica de uma sentença ou proposição, em relação a uma "classe de proposições", deverá ser considerada como a informação pragmática "ideal", com o auxílio de uma pressuposição ficcional de um destinatário ideal, um supersujeito cuja memória abrange toda a lógica, a matemática e todas as sentenças descritivas próprias do domínio de referência da classe de proposições em questão. Se bem afirmam que essa ficção não formará parte do desenvolvimento técnico de seu trabalho, os autores vão a manter a demarcação da informação semântica, nos contornos dessa idealização. A informação semântica é, logo, aquilo que se encontra numa proposição ou sentença "abstraídas as condições pragmáticas de seu uso" (CARNAP, BAR-HILLEL, 1952, p. 3).

$\mathrm{Na}$ abordagem de Floridi (2011), as condições formais da lógica deixarão de ser definidoras da verdade, mas será mantida a exclusão das condições pragmáticas; a informação semântica requer hoje procedimentos capazes de lidar com plurais conteúdos.

Os níveis de abstração são pensados por analogia com as metodologias de programação ${ }^{17}$; trata-se de procedimentos que, a diferença da abstração aristotélica, não conduz à unicidade de uma substância ou essência, mas, a diferencia do perspectivismo nietzcheano; não dá lugar a uma pluralidade indefinida de perspectivas. O conceito que dá

\footnotetext{
${ }^{16}$ Our theory lies explicitly and wholly within semantics. It does not deal, however, with what has been termed by Weaver in his contribution to the afore-mentioned book "the semantic problem" of communication, which, as defined by him, is "concerned with the identity, or satisfactorily close approximation, in the interpretation of meaning by the receiver, as compared with the intended meaning of the sender." We would rather prefer to consider an investigation in which sender and receiver are explicitly involved as belonging to pragmatics. (CARNAP; BAR-HILLEL, 1952, p. 2)

${ }^{17}$ Floridi faz referências à programação por objeto.
} 
ancoragem epistêmica ao método de abstração de Floridi, evidenciando um ponto crucial de suas teorias, é o de modelização (FLORIDI, 2011b, p. 68-69). Os níveis de abstração constituem, por meio de modelos, redes de observáveis (FLORIDI, 2011b, p. 72), ancoradas em compromissos ontológicos, antes de constituir redes de conceitos, que pudessem demandar justificação por meio de compromissos epistêmicos.

Floridi insiste em rejeitar as abordagens da representação e da interpretação (ver, por exemplo, FLORIDI, 2012b, p.30) para o entendimento da informação semântica, utilizando-se dos níveis de abstração para pensar na modelização como o vínculo possível entre o real e os processos de semantização, que são finalmente processos de construção. Lembremos que o agente dos processos de semantização é um designer e não um sujeito epistêmico ligado ao mundo pela representação.

A infoesfera, porém, não é o mundo das idéias platônico, ainda que possa ser aproximada ao mundo 3 ou mundo objetivo de Popper. Para Floridi (2011, 2012), adotando um ponto de vista construtivista, o modelo é a menor distância possível entre o homem e o mundo. O processo de modelização se concretiza como dialética entre o dado (que sustenta a interface dos processos de semantização do real) e a informação (que estabelece a interface do processo de semantização com o processo de gerar conhecimentos).

Numa perspectiva construcionista, as verdades são finalmente projetadas (designed),
de modo que uma informação semântica $p$ pode estar mais ou menos perto de seu
referente $w$ apenas metaforicamente, quando se discutemos princípios (foundations)
de nosso conhecimento do mundo no sentido mais profundo, ou secundariamente,
quando se falar sobre a aproximação entre diferentes bits de informação entre eles
mesmos [...] (FLORIDI, 2012a, p. 305)

Nesse contexto, pode-se considerar que a opção pelo construtivismo ${ }^{19}$ e a rejeição das abordagens epistemológicas (que denomina platônicas), assim como da vinculação da informação com a representação, formam parte de um esforço para sustentar que a validação do conhecimento depende da informação, sendo que a validade da informação depende dos processos de modelização baseados em dados. Podemos afirma que a convocatória filosófica de Floridi adquire sua relevância como uma das abordagens filosóficas do presente. Sua reflexão sobre o dado e a modelização abre um debate ainda não assumido plenamente pela

\footnotetext{
${ }^{18}$ From a constructionist perspective, truths are ultimately designed, so some semantic information $\mathrm{p}$ can be more or less close to its referent w only metaphorically, when discussing the foundations of our knowledge of the world in the deepest sense, or secondarily, whe $n$ talking about the approximation between different bits of information among themselves [...] ( FLORIDI, 2012a, p. 305).

${ }^{19}$ Floridi vai diferenciar uma versão pós-moderna do construtivismo, que estaria associada ao relativismo, de sua própria tese, que denomina construcionismo, e que inclui como uma de suas premissas a afirmação da existência de um mundo exterior independente dos sujeitos de conhecimento
} 
Ciência da informação, mas cujas questões perpassam as condições contemporâneas do conhecer, do comunicar, do lembrar e do esquecer. Quando se pergunta sobre a possibilidade de informacionalização da natureza, por exemplo, carrega no perguntar as questões pela informatização da paisagem pela fotografia digital ou do corpo humano pela tomografia computarizada; quando se pergunta pela informacionalização da ciência, inclui as questões, por exemplo, acerca dos efeitos de plurais e alternativos procedimentos de visualização - que estão multiplicando-se aceleradamente, como técnica e como industria, afetando a produção e transmissão do conhecimento científico, os processos de aprendizagem e outras formas de comunicação social.

Num momento civilizatório em que o Facebook é a maior base de dados sociológicos já conhecida, e a produção científica é avaliada, menos que pelas normas de Merton, e mais por modelos estatísticos inferenciais, entender a relação entre informações, dados e modelos é uma questão importante, na Filosofia, na Ética e na Ciência da Informação. Floridi nos desafia a participar dessa tarefa.

\section{Referências}

BAR-HILLEL, Y.; CARNAP, R. Semantic information. The British Journal for the Philosophy of Science, v. 4, n. 14, p.147-157, 1953.

BAR-HILLEL, Y. Language and information: selected essays on their theory and application. Reading, Mass; London: Addison-Wesley, 1964.

BERKELEY, G. Tratado sobre os princípios do conhecimento humano. São Paulo: UNESP, 2010.

CAPURRO, R. On Floridi's metaphysical foundation of information ecology. Ethics and Information Technology, v. 10, p. 167-173, 2008.

CARNAP, R.; BAR-HILLEL, Y. An outline of a theory of semantic information. Cambridge, Mass.: Research Laboratory of Eletronic, MIT, 1952. p. 82-98. (Technical Report, 247)

CHARDIN, P. T. O fenômeno humano. São Paulo: Herder, 1965.

CHEN, M.; FLORIDI, L. An analysis of information in visualisation. Pre-print. 2012b, Disponível em: <http://www.philosophyofinformation.net>. Acesso em: fev. 2013. A ser publicado en Synthese (2012). 
D'AFONSO, S. On quantifying semantic information. Information, v. 2, p. 61-101, 2011. doi:10.3390/info2010061. Disponível em: <www.mdpi.com/journal/information $>$. Acesso em: fev. 2013.

FEYERABEND, P. Contra o método. Rio de Janeiro: Francisco Alves, 1989.

FLORIDI, L. Information ethics: on the theoretical foundations of computer ethics. Ethics and Information Technology, v. 1, n. 1, p. 37-56, 1999.

Information ethics: an environmental approach to the digital divide. Philosophy in the Contemporary World, v. 9, n. 1, p. 39-45, 2002.

Open problems in the philosophy of information. Metaphilosophy, v. 35, n, 4, p. 554-582, 2004a.

Information ethics: its nature and scope. Pre-print, 2005. p. 1-30 ${ }^{20}$. Disponível em: <http://uhra.herts.ac.uk/bitstream/handle/2299/3001/903256.pdf;jsessionid=ACF1CD18C9A7 52AF58965DD742D4A27C? sequence=1>. Acesso em: ago. 2010.

Understanding epistemic relevance. Erkenntnis, v. 69, n. 1, p. 69-92, 2008.

Biblioteconomia e Ciência da Informação (BCI) como filosofia da informação aplicada: uma reavaliação. InCID: Revista de Ciência da Informação e Documentação, Ribeirão Preto, v. 1, n. 2, p. 37-47, jul./dez. 2010.

A defence of constructionism: philosophy as conceptual engineering.

Metaphilosophy, v. 42, n. 3, 282-304, 2011a. Disponível em:

$<$ http://www.philosophyofinformation.net/publications/pdf/adofpace.pdf $>$. Acesso em: dez. 2012

The philosophy of information. Oxford: Oxford University Press, $2011 \mathrm{~b}$.

Steps forward in the philosophy of information. Etica \& Politica / Ethics \& Politics, v. 14, n. 1, p. 304-310, 2012a. Disponível em:

$<$ http://www2.units.it/etica/2012_1/FLORIDI.pdf>. Acesso em: fev. 2013

Perception and testimony as data providers. 2012b. p 1-30. Pre-print. Disponível em: <http://www.philosophyofinformation.net/publications/pdf/patadp.pdf $>$. Acesso em: fev. 2013.

Semantic conceptions of information. Stanford Enciclopedya of Philosophy, Spring, 2013. Disponível em: <http://plato.stanford.edu/entries/information-semantic/> Acesso em: 26 fev. 2013.

FROHMANN, B. Documentation redux: prolegomenon to (another) philosophy of information. Library Trends, v. 52, n. 3, p.387-407, 2004.

\footnotetext{
${ }^{20}$ Publicado: FLORIDI, L. 2008. Information ethics: its nature and scope. In: HOVEN, J.; WECKERT, J. (Eds.). Moral philosophy and information technology. Cambridge, UK: Cambridge University Press, 2008. p. 40-65.
} 
FURNER, J. Philosophy and the information science. Pre-print, 2008. Submitted to BATE, M. Encyclopedia of Library and Information Sciences. Disponível em:

<http://polaris.gseis.ucla.edu/jfurner/papers/FurnerPhilosophy.pdf>. Acesso em: fev. 2013

HABERMAS, J. Direito e democracia: entre faticidade e validade. Rio de Janeiro: Tempo Brasileiro, 1997. 2v.

HEIDEGGER, M. El ser y el tiempo. México: FCE, 1951.

KUHN, T. S. A estrutura das revoluções científicas. São Paulo, Perspectiva, 1975.

LE MOIGNE, J. L. Les "nouvelles" sciences de I homme et de la société: "les vérités sont choses à faire et non à dècouvrir". Oct. 1997. Disponível em: <http://www.mcxapc.org>. Acesso em: 20 mar. 2003.

STAHL, B. C. Discourses on information ethics: the claim to universality. Ethics and Information Technology, v. 10, p. 97-108, 2008.

WALLERSTEIN, I. What are we bounding, and whom, when we bound social research. Social Research, v. 62, n. 4, p.839-56, 1995.

WERSIG, G.; WINDEL, G. Information science needs a theory of 'Information Action'. Social Science Information Studies, v. 5, p. 11-23, 1985.

WITTGENSTEIN, L. Investigações filosóficas. Petrópolis: Vozes, 1996. 